\title{
SELEÇÃO DE SISTEMAS ERP USANDO A TÉCNICA SQFD
}

\section{Evandro de Souza Fagundes ${ }^{1}$ Lineu Fernando Stege Mialaret ${ }^{2}$}

Resumo: Este trabalho tem o objetivo de adaptar a técnica Desdobramento da Função Qualidade do Software (Software Quality Function Deployment - SQFD), visando auxiliar na escolha de Sistemas de Gestão Empresarial (Enterprise Resource Planning - ERP ou Sistemas ERP) para micros, pequenas ou médias empresas. Para utilizar a técnica SQFD para a seleção de Sistemas ERP deve-se fazer adaptações dos requisitos e especificações da matriz de qualidade, de acordo com as necessidades de clientes.

Palavras-chave: Sistemas de gestão empresarial; Requisitos; Gestão.

\footnotetext{
1 Bacharelado em Administração/Instituto Federal de Educação Ciência e Tecnologia de São Paulo - IFSP Câmpus Jacareí, Brasil. E-mail: evandrosf20@hotmail.com.

2 Bacharelado em Administração/Instituto Federal de Educação Ciência e Tecnologia de São Paulo - IFSP Câmpus Jacareí, Brasil. E-mail: Imialaret@ifsp.edu.br.
} 